\title{
Evaluation of the Results of Balloon Pulmonary Angioplasty in Patients with Chronic Distal Pulmonary Thromboembolic Disease and Pulmonary Hypertension
}

\author{
${ }^{1}$ Department of Cardiology, Care Hospitals, Hyderabad, India \\ 2 Department of Cardiology, Narayana Hrudayalaya Hospital, \\ Bengaluru, India \\ Ind J Car Dis Wom 2021;6:157-164
}

M. Hanumantha Reddy ${ }^{1}$ George Cherian ${ }^{2}$ Bagirath Raghuraman ${ }^{2}$

\author{
Address for correspondence M. Hanumantha Reddy, MBBS, DNB \\ (General Medicine), DNB (Cardiology), Department of Cardiology, \\ Care Hospitals, Hyderabad, India \\ (e-mail: drhanumanthareddycare@gmail.com).
}

\begin{abstract}
Introduction The gold standard curative treatment for chronic pulmonary thromboembolic disease and pulmonary hypertension (CTEPH) is pulmonary thromboendarterectomy (PTE). Balloon pulmonary angioplasty (BPA) is emerging for distal CTEPH patients, where lesion is inaccessible for surgery. This is the first study conducted in Indian patients for evaluating the impact of BPA in patients with distal CTEPH.

Aims and Objectives To evaluate the effect of BPA in patients with distal CTEPH with the help of New York Heart Association (NYHA) functional class and 6-minute walk distance (6MWD). To study decrease in pulmonary artery pressure and improvement in right atrial and right ventricular function with the help of echocardiography.

Material and Methods Study population-CTEPH patients presenting to the hospital during the study interval of 16 months from January 2017 to April 2018. A. Method: This was an observational retrospective and prospective follow-up study. All distal $\mathrm{CTEPH}$ patients after meeting inclusion and exclusion criteria were taken for study. B. Detailed case records containing information on demographics, clinical features and necessary blood and imaging investigations, ventilation/perfusion (V/Q) scan, computed tomography pulmonary angiography (CTPA), right heart catheterization (RHC) study, pulmonary angiogram, and BPA procedure details were obtained for all participants. C. After 8 weeks of last BPA session, patients were assessed clinically and then 6-minute walk test, blood investigations and echocardiography were done.

Keywords

- 6MWD

- BPA

- CTEPH

- PASP

- PTE

- TAPSE

Data Analysis Statistical analysis was performed by using the software SPSS 22.0 version. We used paired $t$-test to test the significant difference in the mean pre- and post-BPA. $p$-value $<0.05$ will be considered as statistically significant.

Results In our study, mean age of presentation was $39.81 \pm 12$ years. Out of 11 patients, 5 were females and 6 were males. Mean duration of symptoms was 40.5 months. The total number of BPA sessions performed were 30 . The minimum number of BPA sessions undergone was 1 and maximum number of BPA sessions undergone by
\end{abstract}

DOI https://doi.org/ $10.1055 / \mathrm{s}-0041-1736257$. ISSN 2455-7854.
(C) 2021. Women in Cardiology and Related Sciences. All rights reserved.

This is an open access article published by Thieme under the terms of the Creative Commons Attribution-NonDerivative-NonCommercial-License, permitting copying and reproduction so long as the original work is given appropriate credit. Contents may not be used for commercial purposes, or adapted, remixed, transformed or built upon. (https://creativecommons.org/ licenses/by-nc-nd/4.0/)

Thieme Medical and Scientific Publishers Pvt. Ltd., A-12, 2nd Floor, Sector 2, Noida-201301 UP, India 
one patient was 5 , with $45 \%$ of patients undergoing 2 BPA sessions. The total number of segmental arteries dilated was 104 . Segmental vessels dilated per each session was 3.46. There was statistically significant improvement in NYHA class and 6MWD after BPA. 6MWD increased from $299 \mathrm{~m}$ to $421 \mathrm{~m}$ ( $p$-value $<0.001$ ). This improvement in functional capacity is strongly associated with the improvement in right ventricular (RV) function (tricuspid annular plane systolic excursion [TAPSE] from $15.3 \mathrm{~mm}$ to $18.9 \mathrm{~mm}$ ) and with the reduction in pulmonary artery systemic pressure (PASP) (from $92 \mathrm{~mm} \mathrm{Hg}$ to $60 \mathrm{~mm} \mathrm{Hg}$ ).

Conclusion In patients with distal CTEPH who undergo BPA, there was statistically significant improvement in 6MWD. These changes correspond to a treatment-induced reduction in pulmonary artery pressure and lend support to use of BPA in patients with distal CTEPH. ECHO and 6MWD can be used for evaluating BPA efficacy and monitoring disease progression.

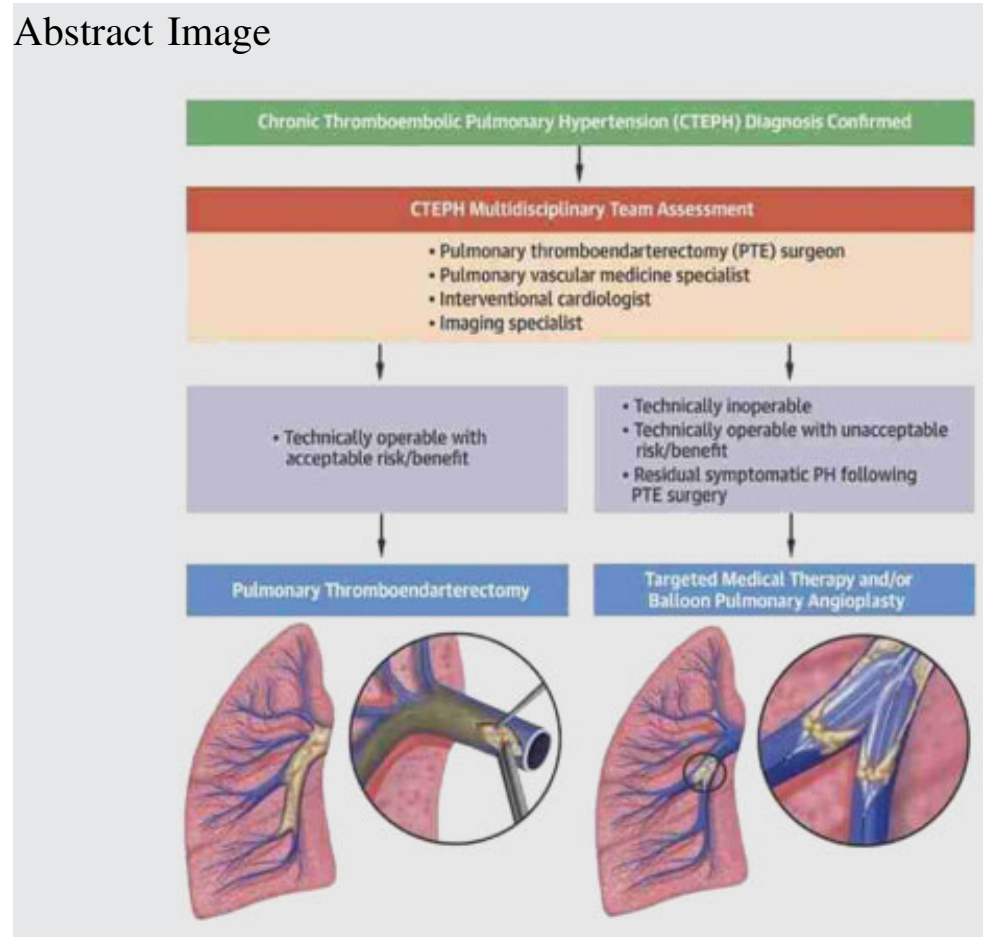

BALLOON PULMONARY ANGIOPLASTY-

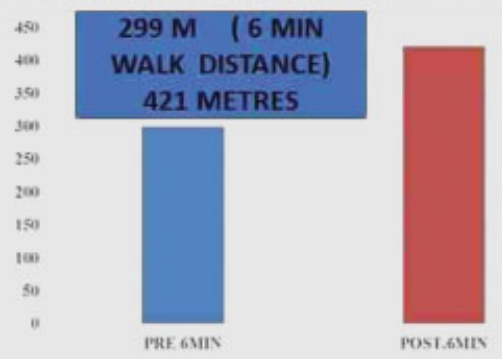

AFTER BPA IN DISTAL CTEPH:

1)NYHA FUNCTIONAL CLASS-IMPROVED. 2)RIGHT VENTRICULAR FUNCTION (TAPSE)INCREASED.

3)PULMONARY ARTERY PRESSURE SIGNIFICANTLY DECREASED.

\section{Introduction}

Chronic thromboembolic pulmonary hypertension (CTEPH) is defined as a mean arterial pulmonary pressure greater than $25 \mathrm{~mm} \mathrm{Hg}$ and pulmonary capillary wedge pressure less than or equal to $15 \mathrm{~mm} \mathrm{Hg}$, which persists for more than 6 months following anticoagulation therapy in the setting of pulmonary emboli (PE). ${ }^{1}$

CTEPH is currently categorized as WHO group 4 pulmonary hypertension. ${ }^{2}$ CTEPH can be cured, unlike other types of pulmonary hypertension (PAH)

CTEPH develops more commonly in patients with prothrombotic states. ${ }^{3}$ In CTEPH lesions, thrombus organizes intraluminally and results in obliteration of pulmonary arteries which, in turn, leads to increased pulmonary vascu- lar resistance (PVR) and pulmonary hypertension, resulting in decreased right ventricular (RV) function and in long-term leads to right heart failure. ${ }^{4}$

Pulmonary endarterectomy (PEA) is the gold standard treatment for patients with CTEPH with favorable longterm prognosis.

Balloon pulmonary angioplasty along with medical therapy is emerging as new therapeutic option for CTEPH patients with distal disease and those with contraindications to surgery.

Echocardiography (Echo) is the first available imaging modality for screening of pulmonary hypertension, but it is challenging due to the complex geometry of the RV. ${ }^{5,6}$

It can be used in measuring pulmonary artery pressure (PAP) and RV function by tricuspid annular plane systolic excursion (TAPSE). ${ }^{6-8}$ 
Common findings of Echo in patient with CTEPH includes RV and right atrial (RA) enlargement, hypertrophy of RV, decreased RV function, tricuspid valve regurgitation, and elevated PAP.

The most sensitive test for diagnosing CTEPH is ventilation/perfusion $(\mathrm{V} / \mathrm{Q})$ scan. $^{9}$ It reveals burden of lung perfusion defect present and even helps in monitoring disease.

Computed tomography pulmonary angiogram (CTPA) helps in diagnosing lung parenchymal disease and has shown sensitivity for detecting CTEPH-related disease in main, lobar, and segmental vessels. ${ }^{10}$

Pulmonary angiography is the gold standard for confirming the diagnosis of CTEPH.

CTEPH lesions angiographically can be classified into five types, depending on lesion opacity and blood flow distal to the lesion, which are as follows: type A-ring-like stenosis, type $\mathrm{B}$-web lesion, type $\mathrm{C}$-subtotal occlusion, type $\mathrm{D}$-total occlusion, and type E-torturous lesion. ${ }^{11,12}$

In CTEPH patients, right heart catheterization (RHC) should be done to measure PAP, RV systolic pressure and RA mean pressure and assess response to vasodilator medications. ${ }^{13}$

The 6-minute walk distance (6MWD) can be used in CTEPH patients, as it corelates well with functional and disease severity.

It can be used in monitoring disease progression and even to assess response to intervention. ${ }^{14-17}$

\section{Treatment}

Multidisciplinary approach should be used to treat CTEPH patients at experienced centers comprising cardiologists and cardiothoracic surgeons. ${ }^{11}$

Lifelong anticoagulation should be given to СТEPH patients; vitamin $\mathrm{K}$ antagonists should be used to maintain international normalized ratio (INR) around 2 to 3.

Pulmonary vasodilators like Riociguat have shown benefit in CTEPH patients by decreasing PAP and PVR and increasing 6MWD. ${ }^{1,18}$

\section{Role of Surgical Therapy (PTE)}

- PTE is the gold standard treatment option for CTEPH patients in whom lesions are accessible for surgery.

- Bilateral PTE is known to improve long-term outcomes in CTEPH patients (-Fig. 1) ${ }^{19-21}$

\section{Role of Balloon Pulmonary Angioplasty}

- Approach to BPA.

- General treatment strategy (BPA procedure steps).

- Identify target lung lesion with largest perfusion defect noted on V/Q scan.

- Femoral vein access was obtained, activated clotting time (ACT) was maintained around (200-250), and 90-cm long sheath was advanced into target pulmonary artery. Judkins guide catheter was passed into target lung region and atraumatic work horse guidewire was used to cross target lesion. Serial balloon (by 2-4 mm size) dilatations were done. Balloons should be undersized to avoid vessel perforation.
- Above steps are repeated for other target regions. ${ }^{22-26}$

- Full treatment usually consists of 4 to 6 separate BPA sessions, separated by 3 to 7 days, and concluded by one final treatment in each lung.

- Any single procedure should not exceed $400 \mathrm{~mL}$ of contrast and $2 \mathrm{~Gy}$ of radiation exposure.

Intermittent $\mathrm{V} / \mathrm{Q}$ scan helps to know improvement in perfusion defects and reprioritize diseased segments.

Reperfusion pulmonary edema (RPE) and pulmonary vascular injury (rupture/perforation) $)^{24}$ are common complications of BPA.

Six-minute walk test and Echo are done at baseline and at regular intervals to monitor disease progression and assess response to BPA.

\section{Clinical Outcomes of BPA}

$B P A$ results in decreased mean pulmonary arterial pressure (MPAP) and PVR and is proportional to number of vessels treated.

In the short-term, BPA is associated with improvements in pulmonary perfusion and increase in 6MWD and exercise capacity $^{7,8,23,24}$

PAH will not normalize immediately after procedure, and it can take few weeks/months to notice positive impacts of BPA. $7,8,24$

Symptom resolution and quality of life improvement is disproportionate to the degree of decrease in pulmonary pressure.

Improvements in cardiopulmonary hemodynamics after procedure leads to RV reverse remodeling and improves RV function.

Presently, for CTEPH patients, BPA has become a primary and adjunctive treatment, and it has shown to improve exercise capacity and cardiac hemodynamics.

\section{Aims and Objectives}

To know the efficacy of BPA in patients with distal CTEPH by monitoring 6MWD and New York Heart Association (NYHA) functional class.

To study reduction in PAP and improvement in RA and RV function by Echo.

\section{Material and Method}

Study area: Department of Cardiology.

Study population: $C T E P H$ patients presenting to the hospital during the study interval of 16 months from January 2017 to April 2018, meeting the inclusion and exclusion criteria of the study.

Sample size and sample technique: We have expected the standard deviation (SD) of the variable 6MWD meters in CTEPH patients who underwent BPA as 80 , and mean values of 6MWD before and after BPA as $403 \mathrm{~m}$ and $445 \mathrm{~m}$, respectively, with $90 \%$ confidence interval $(\mathrm{CI})$ and 90\% power; the minimum required sample size was 22 . 


\section{CTEPH-DIAGNOSED}

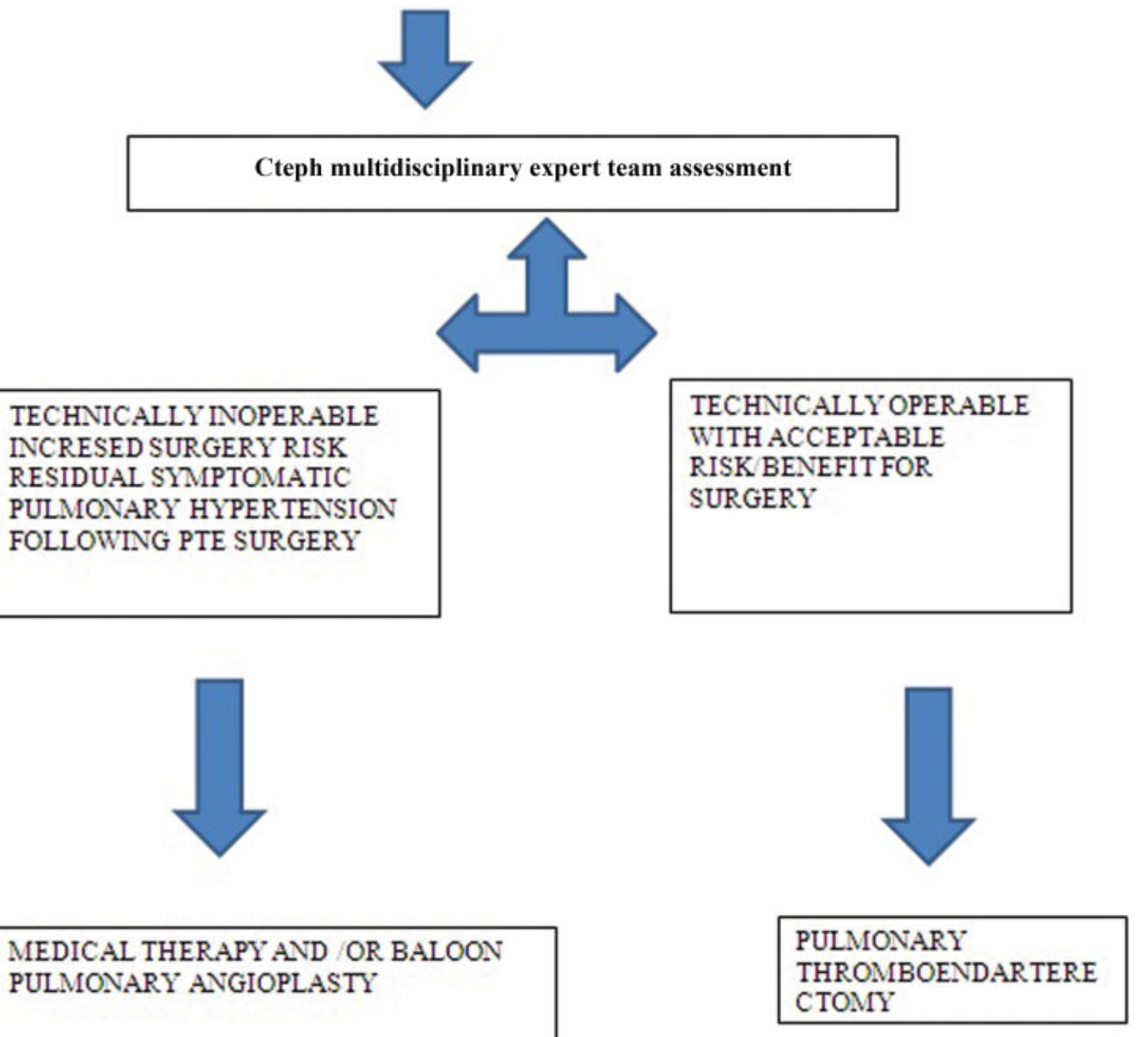

Fig. 1 CTEPH treatment algorithm. ${ }^{11}$

However, during our study, we got only 11 distal CTEPH patients who underwent BPA. As it is a very rare procedure performed, so we got a smaller sample size.

\section{Data Collection Technique and Tools}

Data collection period: January 2017 to April 2018.

\section{Inclusion Criteria}

The study group consisted of CTEPH patients who were considered inoperable by CTEPH team and who underwent BPA during the study period.

\section{Exclusion Criteria}

1). CTEPH patients with proximal thrombi at lobar and segmental levels and who can be treated with PEA.

2). Patients not consenting to participate in the study.

\section{Method}

This was an observational retrospective and prospective follow-up study.

All distal CTEPH patients after meeting inclusion and exclusion criteria were taken for study. 
Detailed clinical history, including blood investigations, Echo, CTPA, V/Q scan, coronary and pulmonary angiogram, RHC study, and BPA session details were obtained for all patients.

After 8 weeks of last BPA session, patients were assessed clinically and then 6MWD, blood investigations, and transthoracic echocardiography were done.

\section{Data Analysis}

Statistical analysis was performed by using the software SPSS 22.0 version.

We used paired $t$-test to test the significant difference in the mean pre- and post-BPA. $p$-value $<0.05$ will be considered as statistically significant.

Institutional ethical committee approval was obtained for this study.

\section{Results and Discussion}

A total of 11 patients were included in the study; 6 were males and 5 were females.

Mean age of presentation was $39.81 \pm 12$ years in our study.

In this study, 40.5 months was mean duration of symptoms.

All patients complained of breathing difficulty, which is a common presentation in CTEPH. One patient had history of hemoptysis (-Fig. 2).

At baseline, 8 patients were in NYHA class 3 and 3 patients were in NYHA class 4.

After BPA sessions, 8 patients were in NYHA class 3 and 3 were in NYHA class 2 ( $p$-value $<0.001$ ). There was significant increase in functional capacity (-Fig. 3 ).

Past history of deep vein thrombosis (DVT) was noted in $27.27 \%$ patients. Hypothyroidism was noted in one patient. Hyperhomocysteinemia was noted in $18.18 \%$ patients.

Overall, thrombophilia conditions were noted in 36.36\% patients.

Acute pulmonary embolism (PE) history was seen in $45.5 \%$ patients. Out of 5 patients of PE, 3 patients were thrombolysed with streptokinase and two were treated by lowmolecular weight heparin (LMWH).

Mean hemoglobin $(\mathrm{Hb})$ before BPA was $14.21 \pm 2.26 \mathrm{~g} / \mathrm{Dl}$ and packed-cell volume (PCV) was $42.18 \pm 6.445$.

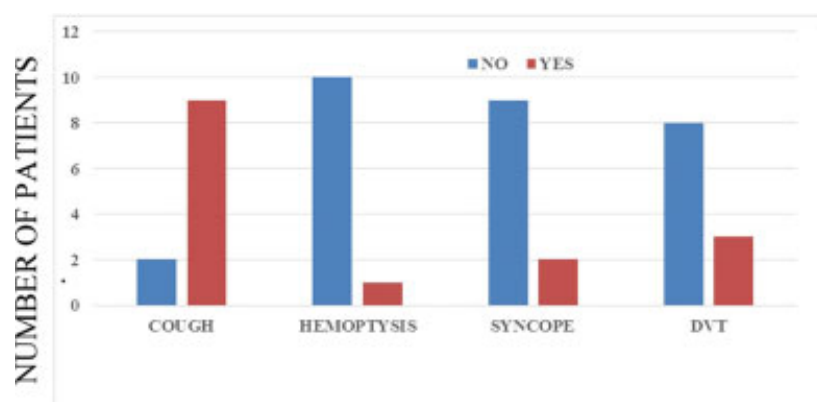

Fig. 2 Symptoms.

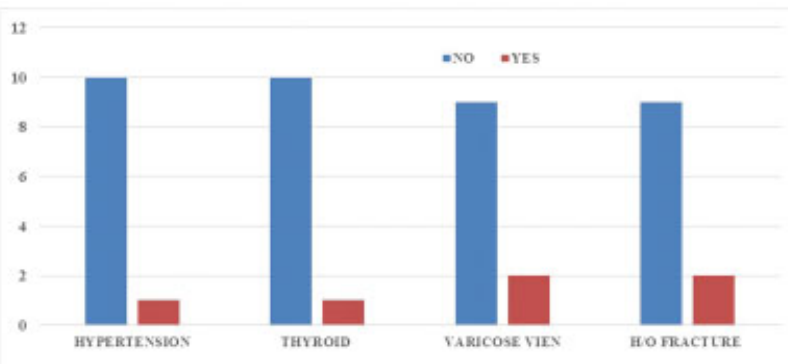

Fig. 3 Associated medical conditions: In number of patients.

Baseline Echo showed RA and RV dilatation and decreased RV function (TAPSE) and elevated PAP. Mean RA minor dimension was $48 \pm 4.074 \mathrm{~mm}$, RV basal diameter was $41.27 \pm 5.60 \mathrm{~mm}$, TAPSE was $15.37 \pm 2.29 \mathrm{~mm}$, and pulmonary artery systolic pressure (PASP) was $92 \pm 31.4 \mathrm{~mm} \mathrm{Hg}$.

CTPA showed diagnostic features of CTEPH in all patients, and it correlated well with pulmonary angiography findings.

During cardiac catheterization, baseline peak PASP was $111.55 \pm 40.31 \mathrm{~mm} \mathrm{Hg}$, which is significantly high as compared with PASP calculated by Echo, which was $92 \pm 31.642 \mathrm{~mm} \mathrm{Hg}$.

Mean right atrial pressure (RAP) by cath was $15.91 \pm 5.069 \mathrm{~mm} \mathrm{Hg}$, and mean RAP measured by ECHO was $13.09 \pm 3.26 \mathrm{~mm} \mathrm{Hg}$.

All CTEPH patients had normal coronary arteries. Right coronary artery was dominant in 10 patients and codominance was noted in 1 patient.

Collaterals are noted in $100 \%$ of patients from different sources like bronchial arteries, aorta and coronary arteries, which is a hallmark of CTEPH. Pulmonary angiography in all our patients revealed segmental and subsegmental disease.

$\mathrm{V} / \mathrm{Q}$ scan revealed mismatched perfusion defects in $90.90 \%$ patients, with high probability of pulmonary thromboembolism, and one patient with low probability, but in that patient, CTEPH confirmed by pulmonary angiography, which is the gold standard for diagnosing CTEPH.

A total of $30 \mathrm{BPA}$ sessions were performed; $45.5 \%$ of patients underwent 2 BPA sessions.

One patient underwent 5 BPA procedures, which was maximum during our study, and only 1 BPA session was done in one patient.

Mean contrast (omnipaque) used was $123.93 \mathrm{~mL}$.

Segmental arteries totally treated during the study period were 104.

A total of 32 segmental arteries were dilated in right lower lobe and 29 segmental arteries dilated in left lower lobe. Twelve segmental arteries were dilated in right middle lobe and 14 in left lingular lobe. Segmental artery dilated in lower lobe of lungs is more when compared with other lung lobes. Segmental vessels dilated before each session was $3.46 \pm 0.86$ ( - Table 1 ).

Only 2 patients developed reperfusion pulmonary edema during the BPA session.

Mild complication requiring only nasal oxygen was observed in one patient, and moderate complication requiring noninvasive ventilation was observed in one patient. 
162 Evaluation of the Results of Balloon Pulmonary Angioplasty Hanumantha Reddy et al.

Table 1 Lobes of lung (number of segmental arteries treated)

\begin{tabular}{|l|l|l|l|}
\hline $\begin{array}{l}\text { Lobes } \\
\text { of lung }\end{array}$ & $\begin{array}{l}\text { Right lung no. } \\
\text { segmental } \\
\text { arteries }\end{array}$ & $\begin{array}{l}\text { Left lung no. } \\
\text { of segmental } \\
\text { arteries }\end{array}$ & $\begin{array}{l}\text { Total no. of } \\
\text { segmental } \\
\text { arteries }\end{array}$ \\
\hline $\mathrm{UL}$ & 7 & 10 & 17 \\
\hline $\mathrm{ML}$ & 12 & 14 & 26 \\
\hline $\mathrm{LL}$ & 32 & 29 & 61 \\
\hline Overall & 51 & 53 & 104 \\
\hline
\end{tabular}

Abbreviations: LL, lower lobe; ML, middle lobe; UL, upper lobe.

Moderate complication was observed in that patient in whom baseline PAP was of suprasystemic level.

There was no pulmonary artery dissection, major vascular complication at access site, or death seen in our patients during or after BPA.

Mean RA minor diameter decreased from $48 \pm 4.074 \mathrm{~mm}$ to $40.36 \pm 6.47 \mathrm{~mm}$, which is statistically significant ( $p$-value $<0.001$ ). Inferior vena cava (IVC) dimension pre BPA $18.82 \pm 3.601 \mathrm{~mm}$ decreased to $9.45 \pm 1.036 \mathrm{~mm}$ post-BPA, which is statistically significant ( $p$-value 0.001 ).

Mean RAP decreased from $13.09 \pm 3.26 \mathrm{~mm} \mathrm{Hg}$ to $7.90 \pm 4.15$ post-BPA, which is statistically significant $(p-$ value $<0.001$ ) (-Table 2).

Resting basal oxygen saturation, pre-BPA $\mathrm{SPO}_{2}$ was $88.91 \pm 3.208 \%$, which increased to $\mathrm{SPO}_{2} 92.18 \pm 1.662 \%$ post-BPA, which is statistically significant ( $p$-value $<0.001$ ).

\section{Discussion}

The 6MWD, even with its own limitations, may better reflect the functional exercise level for daily physical activities. In many centers, it is used to assess response to therapy and prognosis (-Table 3 ).

The present study shows a statistically significant increase in 6MWD and can be compared with other studies.

This improvement in functional capacity is strongly associated with the improvement in RV function as with the reduction in PAP (-Table 4 ).

\section{RV Function Assessment and Pulmonary Artery Pressure Measurement}

The present study shows significant improvement in RV function.

The decrease in RA pressure and RA diameter correlates with increase in RV function post-BPA.

The decrease in RV diameter and increase in RV function indicates reverse remodeling of RV after BPA ( - Table 5 ).
Table 2 Echo parameters pre- and post-BPA

\begin{tabular}{|l|l|l|l|l|}
\hline & & Mean & SD & p-Value \\
\hline \multirow{3}{*}{ PAP mm Hg } & Before & 92.00 & 31.642 & \multirow{2}{*}{$<0.001$} \\
\cline { 2 - 4 } & After & 60.18 & 29.553 & \\
\hline \multirow{2}{*}{ RA mm } & Before & 48.00 & 4.074 & \multirow{2}{*}{$<0.001$} \\
\cline { 2 - 4 } & After & 40.36 & 6.470 & \\
\hline \multirow{2}{*}{ RV (RVBD) mm } & Before & 41.27 & 5.605 & \multirow{2}{*}{0.027} \\
\cline { 2 - 4 } & After & 36.00 & 5.848 & \\
\hline \multirow{2}{*}{ LVIDD mm } & Before & 15.36 & 2.292 & \multirow{2}{*}{0.008} \\
\cline { 2 - 4 } & After & 18.91 & 3.145 & \\
\hline & Before & 37.91 & 6.300 & \multirow{2}{*}{0.134} \\
\cline { 2 - 4 } & After & 40.18 & 5.363 & \\
\hline
\end{tabular}

Abbreviations: BPA; balloon pulmonary angioplasty; LVIDD, left ventricular internal dimensions in end-diastole; PAP, pulmonary artery pressure; RA, right atrial; RV, right ventricular; RVBD, right ventricular basal diameter; SD, standard deviation; TAPSE, tricuspid annular plane systolic excursion.

In our study baseline, PASP $\mathrm{mm} \mathrm{Hg}$ measured by RHC was $111 \pm 40.5$, and mean PAP was $64.09 \mathrm{~mm} \mathrm{Hg}$.

The decrease in PAP was proportional to number of vessels dilated.

When compared with other studies, PAP was higher in our study, which indicates advanced stage of disease when patient initially presented to our hospital.

\section{Limitations of the Study}

- We had only small sample size.

- We lacked the controlled comparison with patients who were treated with medical management or PEA alone.

- In our study, hemodynamic data (PAP) was assessed by Echo in post-BPA sessions.

- We do not have results of long-term follow-up.

- So, further studies at multiple centers are needed to evaluate efficacy of BPA.

\section{Key Messages from the Study}

- We recommend detailed thrombophilia workup of all patients diagnosed with CTEPH.

- We also recommend that all patients diagnosed with PE should be screened for CTEPH if they develop exercise intolerance.

Table 3 6MWD

\begin{tabular}{|l|l|l|l|l|}
\hline $\begin{array}{l}\text { 6MWD } \\
\text { (meters) }\end{array}$ & Fukui etal $^{27}$ & Taniguchi et al $^{28}$ & Present study & ${\text { Mizoguchi et } \text { al }^{29}}$ \\
\hline Pre-BPA & $405 \pm 111$ & $403 \pm 80$ & $299.09 \pm 127$ & $296 \pm 108$ \\
\hline Post-BPA & $\begin{array}{l}501 \pm 109 \\
p \text {-value }<0.001\end{array}$ & $\begin{array}{l}445 \pm 99 \\
p \text {-value }<0.008\end{array}$ & $\begin{array}{l}421.82 \pm 81 \\
p \text {-value }<\mathbf{0 . 0 0 1}\end{array}$ & $\begin{array}{l}368 \pm 83 \\
p \text {-value } 0.01\end{array}$ \\
\hline
\end{tabular}

Abbreviations: 6MWD, 6-minute walking distance; BPA, balloon pulmonary angioplasty. 
Table 4 TAPSE

\begin{tabular}{|c|c|c|c|}
\hline TAPSE $\mathrm{mm}$ & Broch et $\mathrm{al}^{8}$ & Tsugu et $\mathrm{al}^{7}$ & Present study \\
\hline Pre-BPA & $19 \pm 5$ & $17.8 \pm 4.1$ & $15.36 \pm 2.29$ \\
\hline Post-BPA & $22 \pm 5$ & $19.2 \pm 5.4$ & $18.91 \pm 3.14$ \\
\hline$p$-value & $<0.001$ & $<0.23$ & $<0.008$ \\
\hline
\end{tabular}

Abbreviations: BPA, balloon pulmonary angioplasty; TAPSE, TAPSE, tricuspid annular plane systolic excursion.

Table 5 PASP

\begin{tabular}{|l|l|l|l|}
\hline $\begin{array}{l}\text { PASP } \\
\text { Mm Hg }\end{array}$ & $\begin{array}{l}\text { Broch et al } \\
\text { Cath PASP }\end{array}$ & $\begin{array}{l}\text { Mizoguchi et al } \\
\text { Cath PASP }\end{array}$ & $\begin{array}{l}\text { Present study } \\
\text { Echo PASP }\end{array}$ \\
\hline Pre-BPA & $75 \pm 19$ & $81.3 \pm 16.9$ & $92.00 \pm 31.69$ \\
\hline Post-BPA & $58 \pm 15$ & $42.3 \pm 11.9$ & $60.8 \pm 29.53$ \\
\hline$p$-value & $<0.001$ & $<0.01$ & $<0.01$ \\
\hline
\end{tabular}

Abbreviations: BPA, balloon pulmonary angioplasty; PASP, pulmonary artery systemic pressure.

- Transthoracic echocardiography should be done as an initial screening test. If RV dysfunction and elevated PAP are noted, it should be referred to a center which possesses expertise in treating CTEPH cases for further management.

- In CTEPH patients, multimodality imaging should be considered, and it is preferable to do V/Q scan, CTPA, RHC and pulmonary angiography and assess collateral blood supply to lungs before deciding on treatment.

- Balloon pulmonary angioplasty should be considered in patients with distal CTEPH at an expert center.

- It is preferable to keep all hardware ready (different balloon sizes) before performing BPA. It is recommended to dilate only minimal (3-4) number of segmental vessels per each BPA session in order to avoid reperfusion pulmonary edema.

- It is recommended to have an extracorporeal membrane oxygenation (ECMO) team and cardiac surgery team as backups while performing BPA in managing untoward complications.

- All CTEPH patients, even after BPA, should be on lifelong anticoagulants (vitamin $\mathrm{K}$ antagonists), and prothrombin time (PT) and INR should be monitored regularly.

- The 6MWD, can be used to assess prognosis and response to BPA.

- RV function and PAP should be monitored regularly by Echo after BPA to assess response to procedure and frequency, which will depend on the clinical circumstances.

\section{Conclusion}

For CTEPH patients who undergo BPA, there is improvement in 6MWD, and Echo shows RV reverse remodeling and improved function, which is achieved by reduction in PAP and PVR.

So, BPA is recommended in patients with distal CTEPH, which is inaccessible by PEA.

Echo helps in assessing hemodynamic changes and RV function in these patients.
Even after BPA, patients should be on long-term anticoagulants.

\section{Audio 1}

The audio file for this article is avaialble at: https://doi. org/10.1055/s-0041-1736257.10.1055/s-00411736257.

Conflict of Interest

None declared.

\section{References}

1 Edward JA, Mandras S. An update on the management of chronic thromboembolic pulmonary hypertension. Curr Probl Cardiol 2017;42(01):7-38

2 Simonneau G, Gatzoulis MA, Adatia I, et al. Updated clinical classification of pulmonary hypertension. J Am Coll Cardiol 2013;62(25, Suppl)D34-D41

3 Piazza G, Goldhaber SZ. Chronic thromboembolic pulmonary hypertension. N Engl J Med 2011;364(04):351-360

4 Lang IM, Pesavento R, Bonderman D, Yuan JX. Risk factors and basic mechanisms of chronic thromboembolic pulmonary hypertension: a current understanding. Eur Respir J 2013;41(02):462-468

5 Rudski LG, Lai WW, Afilalo J, et al. Guidelines for the echocardiographic assessment of the right heart in adults: a report from the American Society of Echocardiography endorsed by the European Association of Echocardiography, a registered branch of the European Society of Cardiology, and the Canadian Society of Echocardiography.J Am Soc Echocardiogr 2010;23(07):685-713, quiz 786-788

6 Miller D, Farah MG, Liner A, Fox K, Schluchter M, Hoit BD. The relation between quantitative right ventricular ejection fraction and indices of tricuspid annular motion and myocardial performance. J Am Soc Echocardiogr 2004;17(05):443-447

7 Tsugu T, Murata M, Kawakami T, et al. Significance of echocardiographic assessment for right ventricular function after balloon pulmonary angioplasty in patients with chronic thromboembolic induced pulmonary hypertension. Am J Cardiol 2015;115(02): $256-261$ 
8 Broch K, Murbraech K, Ragnarsson A, et al. Echocardiographic evidence of right ventricular functional improvement after balloon pulmonary angioplasty in chronic thromboembolic pulmonary hypertension. J Heart Lung Transplant 2016;35(01): 80-86

9 Tunariu N, Gibbs SJ, Win Z, et al. Ventilation-perfusion scintigraphy is more sensitive than multidetector CTPA in detecting chronic thromboembolic pulmonary disease as a treatable cause of pulmonary hypertension. J Nucl Med 2007;48(05):680-684

10 Sugiura T, Tanabe N, Matsuura Y, et al. Role of 320-slice CT imaging in the diagnostic workup of patients with chronic thromboembolic pulmonary hypertension. Chest 2013;143(04): 1070-1077

11 Mahmud E, Madani MM, Kim NH, Poch D, Ang L. Evolving therapeutic approaches for operable and inoperable disease in CTEPH. J Am Coll Cardiol 2018;71:2468-2486

12 Auger WR, Fedullo PF, Moser KM, Buchbinder M, Peterson KL. Chronic major-vessel thromboembolic pulmonary artery obstruction: appearance at angiography. Radiology 1992;182(02):393-398

13 Jenkins D, Mayer E, Screaton N, Madani M. State-of-the-art chronic thromboembolic pulmonary hypertension diagnosis and management. Eur Respir Rev 2012;21(123):32-39

14 Reesink HJ, van der Plas MN, Verhey NE, van Steenwijk RP, Kloek JJ, Bresser P. Six-minute walk distance as parameter of functional outcome after pulmonary endarterectomy for chronic thromboembolic pulmonary hypertension. J Thorac Cardiovasc Surg 2007; 133(02):510-516

15 Wasser ANK, Hansen James E, Darryl Y, et al. Principles Exercise Testing and Interpretation. 5th ed. Philadelphia: Lippincott Williams and Wilkins; 2011

16 ATS statement: guidelines for the six min walk test. 2002

17 ATS statement for 6 min walk test. Borg scale. AJRCCM: 2016

18 Ghofrani HA, Humbert M, Langleben D, et al. Riociguat: mode of action and clinical development in pulmonary hypertension. Chest 2016

19 Galiè N, Humbert M, Vachiery JL, et al; ESC Scientific Document Group. 2015 ESC/ERS Guidelines for the diagnosis and treatment of pulmonary hypertension: The Joint Task Force for the Diagnosis and Treatment of Pulmonary Hypertension of the European Society of Cardiology (ESC) and the European Respiratory Society (ERS): Endorsed by: Association for European Paediatric and Congenital Cardiology (AEPC), International Society for Heart and Lung Transplantation (ISHLT). Eur Heart J 2016;37(01): 67-119

20 Madani MM, Auger WR, Pretorius V, et al. Pulmonary endarterectomy: recent changes in a single institution's experience of more than 2,700 patients. Ann Thorac Surg 2012;94(01):97-103, discussion 103

21 Madani MM, Jamieson SW. Pulmonary endarterectomy for chronic thromboembolic disease. Oper Tech Thorac Cardiovasc Surg 2006; 11:264-274

22 Feinstein JA, Goldhaber SZ, Lock JE, Ferndandes SM, Landzberg MJ Balloon pulmonary angioplasty for treatment of chronic thromboembolic pulmonary hypertension. Circulation 2001;103(01):10-13

23 Sugimura K, Fukumoto Y, Satoh K, et al. Percutaneous transluminal pulmonary angioplasty markedly improves pulmonary hemodynamics and long-term prognosis in patients with chronic thromboembolic pulmonary hypertension. Circ J 2012;76(02): 485-488

24 Kataoka M, Inami T, Hayashida K, et al. Percutaneous transluminal pulmonary angioplasty for the treatment of chronic thromboembolic pulmonary hypertension. Circ Cardiovasc Interv 2012;5 (06):756-762

25 Inami T, Kataoka M, Yanagisawa R, et al. Long-term outcomes after percutaneous transluminal pulmonary angioplasty for chronic thromboembolic pulmonary hypertension. Circulation 2016;134 (24):2030-2032

26 Shimura N, Kataoka M, Inami T, et al. Additional percutaneous transluminal pulmonary angioplasty for residual or recurrent pulmonary hypertension after pulmonary endarterectomy. Int J Cardiol 2015;183:138-142

27 Fukui S, Ogo T, Goto Y, et al. Exercise intolerance and ventilatory inefficiency improve early after balloon pulmonary angioplasty in patients with inoperable chronic thromboembolic pulmonary hypertension. Int J Cardiol 2015;180:66-68

28 Taniguchi Y, Palanche O, Bourkhis S, Rangheard AS, Parent F. Sitbon Oet al. Refined balloon pulmonary angioplasty of the treatment of non-operable CTEPH: initial experience in a CTEPH center. hospital biocetre, University Paris-sud, France. ICA Belgium 2017

29 Mizoguchi H, Ogawa A, Munemasa M, Mikouchi H, Ito H, Matsubara $\mathrm{H}$. Refined balloon pulmonary angioplasty for inoperable patients with chronic thromboembolic pulmonary hypertension. Circ Cardiovasc Interv 2012;5(06):748-755 